\title{
Research Knowledge Transfer through Business-Driven Student Assignment
}

\author{
Corina Sas \\ Computing Department \\ Lancaster University \\ Infolab21, South Drive, LA1 4WA \\ corina@comp.lancs.ac.uk \\ Phone: ++44 (0) 1524510318 \\ Fax: $\quad++44(0) 1524510492$
}

\begin{abstract}
Purpose - This paper presents a knowledge transfer method which capitalises on both research and teaching dimensions of academic work. It also proposes a framework for evaluating the impact of such a method on the involved stakeholders.
\end{abstract}

Design/methodology/approach - The case study outlines and evaluates the six stage process of addressing a business-driven problem through translating it into a research question addressable by students in their learning context. The stakeholders involved in this process are a) an academic who is also the process coordinator, b) her students who are involved in a Master by Research programme, and c) a small size enterprise (SME).

Findings - This approach to knowledge transfer offers clear benefits for all its stakeholders. It provides the company with research solutions that can be used to improve the profitability and increase the company competence base. The academic benefits from leading students' research and enabling a better teaching/learning process, while students benefit from learning by doing which involves applying research knowledge and skills in an industrial project. Apart form these benefits the paper also highlights the lessons learned and the understanding gained into how this approach can be successfully replicated.

Research limitations/implications - The case study approach undertaken for this exploratory research cannot ensure the generalisation of the study findings.

Originality/value - Traditionally, knowledge transfer has exploited the research component of academic work while neglecting the potential of its teaching component. By exploring the synergy between research and teaching, the proposed method not only enables research knowledge transfer but it also leads to better quality of the teaching process.

Keywords: knowledge transfer, small and medium-sized enterprises, student assignment, research.

Article Type: Case study

\section{Introduction}

Studies have shown that knowledge transfer from higher education to business is highly beneficial because it leads to innovation and regional development [7][13][19]. Unfortunately this is a often a challenging process since universities and business are different institutions, both in terms of the rationale for and ways in which they generate knowledge. While higher education institutions are focused on scientific 
research and discovery, companies are interested in applying knowledge to specific problems for increased profitability [23].

From these different motivations originates the tensions characterising the traditional dialog between researchers and practitioners. In order to address these tensions and reconcile divergent perspectives for mutually beneficial collaboration, one has to explore the context that can facilitate knowledge transfer from academia to industry. As Brown and Duguid [8] indicated, university is at its most effective when it conducts research that the companies are unable or unwilling to undertake. Traditionally academic-industry links have emerged through spin-outs from universities, or contracted research performed by universities on behalf of the industry. Usually these demand either considerable amount of time that the academics have to buy to perform the research themselves, or to prepare grant applications to ensure funding for employing research assistants. Given this high financial cost, it is surprising that the teaching component of the academics' work is seldom included in these forms of knowledge transfer. The only exception is the consultancy assignment [21], or work-based learning [10], but in this case, the research component is usually ignored.

We present a method of knowledge transfer which exploits the synergy between research and teaching as fundamental domains of academic work. It takes the form of a student assignment with the added value of the research component. Besides being driven by a business problem, the assignment is chosen and formulated so that it also addresses a valid research question. It is this research question and the research methodology employed for tackling it which contributes to the originality of the proposed path of knowledge transfer. This method is consistent with the view that research ethics are better guarded when researcher has full control over the research process and outcomes, rather than being paid by a research consumer [21].

The following section introduces several theories from business management literature that can be used to explain the basis of cooperative partnership between academia and industry. The subsequent section presents the case study where the stakeholders are introduced and the process of knowledge transfer is further detailed. This is followed by the stakeholders' evaluation of the process itself, together with a proposed framework for evaluating the impact of such knowledge transfer on its stakeholders.

\section{Background}

\section{Theories explaining strategic alliances}

Collaborations between academia and industry that support knowledge transfer can be described in terms of strategic alliances. These represent enduring co-operative arrangements between organisations which employ resources for the joint accomplishment of individual goals of each organisation [5]. Alliances are based on reciprocity, with objectives based on each partner's agreement, commitment and resources. Three of the theories developed in business management literature are introduced below (for an excellent review see [5]). These theories have been selected because they can inform the conceptual underpinning of our proposed method of knowledge transfer.

\section{Economic Theory}

Based on both mainstream and transaction cost economics this theory considers the involvement of a company in strategic alliances as being driven by increased efficiency that cannot be attained through the company own resources. Such a theory 
emphasises the economic rationales for partnerships while discounting any other motivation found in practice [9][14].

\section{Learning Theory}

According to this theory, companies engage in strategic alliances to learn and expand their knowledge and competence base [17][18]. In this context, the distinction between procedural knowledge and declarative knowledge that has long been acknowledged in many theories of learning and cognition [1][2][23] becomes relevant. Through offering a descriptive representation of knowledge, declarative knowledge expresses facts [25]. In opposition, procedural knowledge cannot be easily accessed and verbalised. It forms part of a mental model which enables task execution because of the technical skills capturing the "knowing-how"[3]. For these reasons, procedural knowledge needs to be internally developed and strategic alliances with partners that can assist in this process, play an important role in knowledge transfer. This theoretical perspective does not consider the costs associated with organisational learning and knowledge transfer.

\section{Social Network Theory}

This theory accounts for the rich social context that favour social alliances by promoting the idea that alliances are driven by the social networks of prior relationships, as opposed to company's independent search for alliance partners [6][16]. Such prior relationships provide a rich base of knowledge regarding potential partners' competencies, matching interests as well as ability to work together. The network enables its members' access to the so-called social capital representing the resources that a company can draw from alliance relationships.

These theories apply differently to each members of the academia-industry partnership. Since this relationship is initiated to address (through research) the company's specific problems, at face value, the company is at the receiving end, while the academic partner - at the giving end. Through the solutions researched and proposed by the academic partner, the company hopes to enlarge its competence base and more importantly, increase its efficiency. The academic partner can exploit the partnership through performing applied research that can be further disseminated and through improving the quality of teaching process. Given the strong ties required by such collaboration, both partners should belong to the same social network.

Other factors supporting successful collaborations between academic and industrial partners through the proposed method of knowledge transfer, are summarised below. Given the different mind-sets that academic and industry partner bring into the collaboration, there is an increased need for perspective taking, as a recognition of differences between knowledge, values, assumptions and beliefs [20]. This indicates that practitioners will incorporate research findings only if they are relevant and interpretable by the business community. This requires both parts to broaden their perspective: researchers should be able to interpret and communicate their findings so that they are meaningful to practitioners, who in turn should be able to support research, as well as understand and apply research findings. A theoretical framework that supports the understanding of multiple perspectives is stakeholder theory [12]. According to this, participants in the collaboration for knowledge transfer need to be aware of each other's goals and able to negotiate their understanding and desired outcomes [19]. Perspective taking requires specific context which brings together all the partners involved in collaboration. In such joint interpretative forums [20], the 
meaning is shared and negotiated, while learning is facilitated through opportunities for reflections [4].

The following section describes the proposed method for knowledge transfer, i.e. addressing a business problem through student assignment, as well as highlighting the major stakeholders, the process, and its major challenges.

\section{Case study}

\section{Stakeholders}

The case study presents a partnership between the Computing Department and the company Escendency both located in InfoLab21 at Lancaster University. This collaboration was facilitated by the Knowledge Business Centre (KBC), an experienced enabler for academic-industrial collaboration.

\section{$S M E$}

Escendency is a recently formed company developing a web-based performance improvement system to enable public sector organisations to measure strategic performance, and make sustainable progress towards their common vision. For this, client organisations are required to identify their vision. Such high level objective will be iteratively broken down in lower level objectives so that any given level makes up $100 \%$ of the objective immediately above it. This process continues until the objectives can be directly measured through performance indicators. Action plans are used to monitor the organisation progress from performance indicators to objectives. The system also links the people in the organisation to the performance measures and action plans they are responsible for.

There have been two major aspects which motivated the Escendency company to seek out academic collaboration. It lacks the expertise to carry out needed research, and has limited financial resources which exclude commissioning academic work for addressing some of the problems it faces. As mentioned by the Escendency CEO, a common problem encountered when the system has been presented to potential clients is how to accurately convey a clear representation of the system. In order to support this intuitive understanding, the company has developed an animated representation which visualises metaphorically the conceptual model of the system. However, this work has been performed without any research into the fields of interaction design or metaphor visualisation. Therefore there is a need to refine the metaphor of the Escendency conceptual model so that it can be better understood by the current and potential clients. This requires the evaluation of the current metaphor together with the exploration of alternative metaphors. In addition, since the company intends to reach out new markets, the metaphor should be able to convey domain-independent representations.

\section{Academic}

The academic involved in this collaboration is a lecturer in Human-Computer Interaction (HCI) in Computing Department, University of Lancaster. As a lecturer, she has developed, taught and assessed several HCI courses ranging from first year undergraduate to Masters level.

\section{Students}

The teaching course that was selected as a framework for this knowledge transfer is the Advanced Interactive System Design (AISD) module for the students enrolled in the Master by Research which is a HCI oriented programme. The AISD module focuses on the development of research knowledge and skills in designing, prototyping and evaluating interactive systems. It involves a teaching component in 
the form of a one week intense block mode, and a coursework component which is designed to support a constructivist approach to learning [11][22]. For the coursework, the students receive a design brief and are required to work both in group and individually to design the required system. By the end of the module, students produce low fidelity prototypes. The assessment procedure involves two individual reports in which students reflect on their individual and groupwork respectively. Through exposing the students to a design brief based on a business problem, they become stakeholders in the academia-industry collaboration.

\section{The process of knowledge transfer}

This section describes the multi-stage process enabling the collaboration and ultimately the knowledge transfer. Within this process, the central role of the academic among the partnership stakeholders cannot be overemphasised. The academic can be seen as linking the company - who provides the problem, and the students - who explore the solutions, while carefully directing the problem definition that meets the constraints of each of the stakeholders. The academic is responsible in the first phase for successively translating the problem from the original business language into a research questions and ultimately in a course assignment. In the second phase, the academic has to translate the solutions provided by the students in their coursework into meaningful research findings and in the accessible language to be understood by the company representatives. In addition, the academic has to coordinate students work as well as their communication with the company partner. The following stages are presented from the perspective of the academic involved in the collaboration.

1) Understanding the business vision, aims and objectives and in particular the specific problems that hinder the current system development.

Intense communication took place between the academic and the company representatives. This consisted of presentations, demos, and question sessions that enabled the academic to understand the company goal. The system website as well as the online documentation represented additional resources that helped clarifying outstanding issues. During the communication process, different avenues for collaboration were explored and subsequently discarded because of the lack of company's resources. From the specific problems that hindered the system development both partners were interested in selecting those which fall under the remit of the academic's interests, while capitalising on both her research and teaching expertise. Such HCI type of problems included the assessment of the system's overall usability and in particular interface usability, the behaviour and representation of various icons on the interface, the development of a library of interface icons, as well as visualisation of system metaphor, all with the purpose of supporting users to accept the system and the change that it promotes in the organisation.

2) Narrowing down to a couple of such problems and selecting the one with greatest research potential.

Among the previously identified business problems, the visualisation of system's metaphor was selected to be addressed. This choice enabled the highest research component to be brought into the collaboration while being sufficiently open-ended. At the same time, the expected outcome of its solution would not only support the better understanding of the Escendency conceptual model by its current clients, but also the development of a better marketing tool to promote this conceptual model to new potential clients in different application domains. This process required several communication sessions where both the academic and the company representative 
became aware of each other's perspectives and constraints. For this, a joint interpretative forum needed to be established. Two months of weekly meetings between the academic and a company representative took place in order to negotiate the objective of the alliance and share its understanding.

3) Translating the identified problem from a business perspective into a scientific inquiry, e.g. as a research question.

An in-depth preparation enabled by the previous stage contributes to the ease of translating the business problem into the language of scientific inquiry. This stage is considerably easier if the academic's research interests successfully circumscribe the business problem. However, since business-driven problems can seldom be confined to one discipline or methodological approach, this stage requires the academic to cover also areas that are outside her expertise. Arguably challenging, this stage forces the academic to seek creatively research questions that transcend disciplinary boundaries [15]. This in turn can lead to an inquiry that involves meaningful, well motivated and original research, thus increasing the academic's benefit of collaboration.

4) Translating the research question in terms of learning objectives and teaching assignment.

The problem to be addressed needs to support the course learning outcomes, be doable in the assignment time frame, and not at least assessable. Once the research question is identified and agreed upon it should be formulated to match the requirements encapsulated in the course assignment. In addition, the assignment difficulty should match students' previous knowledge and skills. This also involves providing students with a road map of the essential steps that need to be performed for carrying out the research activity. Various research methods need to be selected and outlined. At this stage, specific questions regarding the study procedure and participants need to be clarified and mutually agreed by the stakeholders. Students' access to real users would have allowed them to observe working practices and to interview employees about their conceptual model of the Escendency system. However, such access has not been ensured during the project duration so that design brief has been revised to include more accessible participants, i.e. university students. This led to unexpected delay in delivering the brief which in turn forced us to postpone the date of the assignment due.

5) Introducing the course assignment to students and monitoring their progress.

For this stage, the academic organised a meeting with all the stakeholders, where the students were given a presentation of the design brief. The aim of the brief was to investigate how the conceptual model of the Escendency system can be visualised and offered in the form of metaphors to a new user group, in a different application domain. This presentation was followed by one of the Escendency CEO who introduced the conceptual model of the system and highlighted the relevance of the visualisation metaphor. The students received additional reading material and were encouraged to ask questions. This stage involved also monitoring students' progress on the given assignment.

6) Assessing student work and preparing a report for the company.

Despite the project challenges and the additional communication problems encountered during its life cycle, the quality of students work was high. Besides gaining a thorough understanding of the conceptual model of the Escendency system, the students developed and evaluated nine metaphors encapsulating this model. Their work also highlighted some of the weaknesses of Escendency current metaphor. 
These relate to its rigid structure which restricts performance definition to only one objective.

\section{Subjective evaluation of the proposed method}

The evaluation of the proposed knowledge transfer method involved a dialogue between the academic on the one hand, and the students and company representatives on the other hand. For this purpose we employed both interviews and questionnaires.

The main problems highlighted by students relate to the project goal and constraints. As mentioned before, the course assignment needed to be revised because the company representatives have encountered difficulties in involving their clients in this project. The most accessible study participants are usually recruited from the student population. However, a field study involving student participants as opposed to Escendency users led to a shift of emphasis from organisational to individual goals. Although mentioned during the introduction of the design brief, this compromise has not been sufficiently emphasised. Once rediscovered by the students, it led to their initial disengagement with the project. Students' lack of communication prevented the academic to address the issue in time. A clearer emphasis on the limitations of the design brief together with a clearer description of why the project does not involve real Escendency users would have allowed the students to better shape their expectations regarding the assignment.

Another stumbling block encountered by the students related to the given conceptual model of the Escendency system which needed to be critiqued. Once the students have identified flaws within the Escendency conceptual model, these flaws were perceived as constraints to be refuted rather than challenges to creatively explore the design space in order to address them. This problem highlighted the need for emphasising within the learning outcomes of the assignment, not only knowledge and skills, but also the role of values such as awareness of the problem complexity, openmindedness rather than righteous attitude towards handling uncertainty as well as acceptance of limited control over the implementation of their research findings [10]. The company saw this collaboration as a success, as highlighted in its feedback on the report prepared by the academic to summarise the project outcomes: "Excellent report. We now have a visualization capability which means that we can actually implement pretty pictures in the system. We are also currently building an e-learning tool which will also be used in marketing, so we have the capability of actually implementing these metaphors and using them productively, which makes this report even more valuable".

The greatest challenge for the company was attracting real clients to become stakeholders in this collaboration and host the field study. One suggestion for improving the quality of this partnership consists of involving the students earlier in the collaboration: "Maybe the process would have been more efficient if some of what was done later was done earlier - namely, involving the students directly in discussions. Early discussions were actually two steps away from the students, and I think the system worked pretty well. Maybe, however, as part of the taught part of the course, a general brainstorming of potential projects could help to clarify the state of industry as well as desired outcomes of the course for industry". Indeed, enabling students' access to the preparatory stage of the project, alongside with the academic and the company representatives would allow students to develop the proper sets of attitudes and values required by an industrial project as well as shaping their expectations for its outcomes. The second suggestion solicited earlier feedback from 
the student work so that it can be exploited before the deadline of this project and thus to overcome the limitation of the lengthy project duration.

\section{Discussion}

The above evaluation of the proposed method of knowledge transfer is further refined, through a reflection on the various aspects which shape the effectiveness of its impact on each stakeholder. For this, the impact has to be assessed on each of the involved stakeholders: company, academic, and students, in terms of benefits, costs and risks

\begin{tabular}{c|l|l|l|}
\multicolumn{2}{c}{ Company } & \multicolumn{2}{c}{ Academic } \\
\cline { 2 - 4 } Benefits & $\begin{array}{l}\text { Factual } \\
\text { solutions } \\
\text { Tacit knowledge: process } \\
\text { Skills: communication }\end{array}$ & $\begin{array}{l}\text { Knowledge and skills: } \\
\text { leading and supervising } \\
\text { research, designing } \\
\text { better teaching process, } \\
\text { networking and outreach } \\
\text { activity, communication } \\
\text { Academic papers }\end{array}$ & $\begin{array}{l}\text { Knowledge and skills: } \\
\text { learning by doing, } \\
\text { applied research, } \\
\text { communication } \\
\text { Better grades }\end{array}$ \\
\cline { 2 - 4 } Costs & $\begin{array}{l}\text { Time for preparing and } \\
\text { assisting the assignment }\end{array}$ & $\begin{array}{l}\text { Time for preparing and } \\
\text { assisting the assignment }\end{array}$ & $\begin{array}{l}\text { If well delivered, no } \\
\text { extra cost }\end{array}$ \\
\cline { 2 - 5 } Risks & $\begin{array}{l}\text { Communication failure } \\
\text { Involving real clients }\end{array}$ & Communication failure & $\begin{array}{l}\text { Communication failure } \\
\text { Loss of motivation }\end{array}$ \\
\cline { 2 - 5 }
\end{tabular}

Figure 1. Framework for evaluating the impact of the proposed method of knowledge transfer through business-driven student assignment

\section{The benefits of knowledge transfer process}

The company became an active participant in the research process rather than being merely a consumer. The transferred knowledge consists of both in factual data, i.e. the outcomes of the research process, and tacit knowledge, i.e. learning to work with academics, and knowledge about the research process itself. The solutions provided by the research carried out through student assignment can be used to improve the company's profitability (economic theory) and increase its competence base in addressing similar future problems (learning theory). The latter involves experience for working with an academic on student assignments which helps shape future expectancies on similar collaborations. Six months after the report has been delivered, the company has successfully used some of the proposed metaphors in its marketing activities. Other potential benefits for the company include satisfaction for having contributed to learning in higher education, as well as the opportunity to identify potential employees among students.

The benefits for the academic are analysed along three main dimensions which define academic work: research, teaching and networking. Research-wise, this collaboration enabled the academic to lead students' research in an area of interest as well as to exercise control over the content being learned. HCI research topics such as visualisation and metaphors can be further exploited in academic papers. This knowledge transfer method also supports the teaching process through real world experience and transferable skills that it enables. Not at least developing links with industry can foster future collaborations. Thus, this partnership for knowledge transfer can be seen as part of the academic's networking (social network theory) and outreach 
activity. One way to increase the academic benefit from such collaboration is to define university incentives which recognise the outreach activity as being an essential part of the promotion process.

For students, the benefits of this form of knowledge transfer resides in learning by doing which offers the opportunity to apply their research knowledge and skills, and to develop transferable skills together with the ability to bridge the gap between theory and practice. Within this proposed method, the academic project is replaced by an industry project. The rationale and objectives are based on the company needs, but the work itself is research-led performed in an academic context. In this way, the proposed method brings authentic problems in the context of the academic teaching, ensuring students satisfaction of doing a real job rather than a pure academic exercise.

\section{The costs of knowledge transfer process}

Although the proposed method for knowledge transfer does not involve monetary cost, it still requires time investment from each stakeholder.

The company representatives need to make time for introducing the system to the academic and students, for negotiating with the academic the problem to be addressed as well as the project requirements and objectives.

The academic's time is required at each stage of this process primarily for establishing and maintaining links with the company. Initially the time is required to understand the system, its problems and to identify the research topic. After that, the academic should be able to support and monitor students' progress and not at least, should be able to make the research findings available to the company and liaise with its representatives on identifying proper ways for exploring these findings. The academic's investment of time is clearly higher than for a normal student assignment, but we argue that the benefits outweigh the costs, i.e. fabricated design briefs will seldom lead to the same learning outcomes as the real ones.

If well managed, the students cost involved in this industry-based project should not be higher than the time invested in a traditional academic project. The difference, which can lead to additional efforts, relates to the challenges associated with this assignment.

\section{The risks of knowledge transfer process}

The critical factors contributing to the success of this approach is communication needed to match the requirements of each stakeholder. The leading role in this approach belongs to the academic who needs to communicate both with the business and students. Relevant for this is the rapport between the academic and business people based on mutual trust, commitment, match between academic's interests and expertise, and company's goals, objectives or problems, as well as academic's interest to network and reach out practitioner community. The successful links have in common flexibility, rapid response, timely delivery and management skills. This communication proved to be time consuming and sometimes inefficient. Ensuring direct communication between business and a student representative would reduce the time required for arranging meetings.

Several lessons have been learned that can improve future such collaborations. Addressing the gap between different perspectives requires that the different stakeholders creatively solve the issues of research content, research process and dissemination [24]. From students' perspective, this study showed that insufficient communication and lack of proactive attitude can seriously hinder their learning process. Therefore, there is a strong need for a better student preparation for this 
collaboration. They need to be informed not only about the project content but also about how it differs from a traditional academic project. In this way, their involvement in the project could be more responsible, proactive and with the right level of expectations. In addition, the students need to be involved earlier in the collaboration and made aware of the efforts made to reach a satisfactory solution able to accommodate the constraints of the industrial partner. This will ensure that the communication process will flow easier between each pair of stakeholders and rely less on the academic as an informational hub. Given the complexity of business environment, the preparation time for such an assignment is longer than usual. Thus, to ensure clients involvement, we recommend that preliminary discussion start a couple of months earlier.

\section{References}

[1] Anderson, J. (1976). Language, Memory, and Thought. Lawrence Erlbaum, Hillsdale, NJ.

[2] Anderson, J. (1983). The Architecture of Cognition. Harvard University Press, Cambridge, MA.

[3] Anderson, J. (2000). Cognitive Psychology and Its Implications. Worth Publishing, New York.

[4] Argyris, C. and Schön, D. (1974) Theory in practice: Increasing professional effectiveness, San Francisco: Jossey-Bass

[5] Bannerman, P., Spiller, J., Yetton, P., Davis, J. (2005). Strategic Alliances in Education and Training Services. A Literature Review. Australian Government. Department of Education, Science and Training.

[6] BarNir, A. \& Smith, K.A. (2002). Interfirm Alliances in the Small Business: The Role of Social Networks. Journal of Small Business Management, 40(3), 219-232.

[7] Blaxter, L, Hughes, C \& Tight, M. (1998). Writing on academic careers, Studies in Higher Education. 23(3), 281-295.

[8] Brown, JS and Duguid, P (2000) The social life of information, Harvard Business School, Cambridge, MA.

[9] Buckley, P.J. \& Casson, M. (1988). A Theory of Co-operation in International Business. Management International Review, 28(Special Issue), 19-38.

[10] Burn, G.R. and Robert, R.P. (2005). Supported Workplace Learning:a knowledge transfer paradigm. Policy Futures in Education, 3(1) 50-61.

[11] Dix, A, Finlay J, Abowd G and Beale R. (2003). Human-Computer Interaction, 3 rd Edition. London: Prentice Hall.

[12] Freeman, R.E. (1984). Strategic Management: A stakeholder approach. Boston: Pitman.

[13] Fukugawa, N. (2005). Characteristics of knowledge interactions between universities and small firms in Japan. International Small Business Journal. 23(4), 379-401.

[14] Glaister, K.W. \& Buckley, P.J. (1996). Strategic Motives for International Alliance Formation. Journal of Management Studies, 33(3), 301-331.

[15] Hodgkinson, G.P., Herriot, P., Anderson, N. (2001). Re-aligning the Stakeholders in Management Research: Lessons from Industrial, Work and Organizational Psychology. British Journal of Management, Dec2001 Supplement 1, Vol. 12, 41-49. 
[16] Hutt, M.D., Stafford, E.R., Walker, B.A. \& Reingen, P.H. (2000). Case Study: Defining the Social Network of a Strategic Alliance. Sloan Management Review, 41(2), 51-62.

[17] Inkpen, A.C. (2000). Learning through Joint Ventures: A Framework of Knowledge Acquisition. Journal of Management Studies, 37(7), 1019-1043.

[18] Iyer, K.N.S. (2002). Learning in Strategic Alliances: An Evolutionary Perspective. Academy of Marketing Science Review, 10, 1-14.

[19] Johnson, D. and Tilley, F. (1999). HEI and SME Linkages: Recommendations for the future. International Small Business Journal. 17(4), 66-81.

[20] Mohrman, S.A., Gibson, C.B., Mohrman, A. M. (2001). Doing research that is useful to practice: A model and empirical exploration. Academy of Management Journal. 44(2) 357-375.

[21] Ormerod, R. (1996). Combining management consultancy and research. Omega, International Journal of Management Science. 24, 1-12.

[22] Sas, C. (2006). Learning Approaches for Teaching Interaction Design. HCI Educators Workshop.

[23] Slusarz, P. and Sun, R. (2001). The interaction of explicit and implicit learning: An integrated model. In Proceedings of the 23rd Cognitive Science Society Conference, pages 952-957, Mahwah, NJ. Lawrence Erlbaum Associates.

[24] Starkey, K. and Madan, P. (2001). Bridging the Relevance Gap: Aligning Stakeholders in the Future of Management Research. British Journal of Management 12 (s1), S3-S26.

[25] Turban, E. and Aronson, J. (1998). Decision Support System and Intelligent Systems. Prentice Hall, Upper Saddle River, NJ. 